Gomez, C.P., and Hamid, H. (2018). "ISO and lean can contribute to a culture of continuous improvement." In: Proc. $26^{\text {th }}$ Annual Conference of the International. Group for Lean Construction (IGLC), González, V.A. (ed.), Chennai, India, pp. 305-315. DOI: doi.org/10.24928/2018/0270. Available at: www.iglc.net

\title{
ISO AND LEAN CAN CONTRIBUTE TO A CULTURE OF CONTINUOUS IMPROVEMENT
}

\author{
Christy P. Gomez ${ }^{1}$ and Hashima Hamid ${ }^{2}$
}

\begin{abstract}
There is increasing "acceptance" that compliance to International Organization for Standardization (ISO) Quality Management Systems is adequate to secure the full benefits of continuous improvement (CI) practice. This appears to detract construction organizations from developing CI practice that can significantly contribute to a culture of CI. This paper proposes that implementation of the Last Planner System ${ }^{\circledR}$ (LPS) for improving construction project planning and scheduling (P\&S), based on lean construction's TFV theory, can contribute to CI culture within an ISO QMS compliance framework. It is argued that claims regarding lean construction as being amongst one of the many construction improvement 'panaceas' that are non-contextual, generic solutions that are reductionist 'bolt-on' models of change are rather unfounded.

In order to substantiate the above argument a CI maturity model was developed based on CI critical success factors based on a Delphi survey, and the CI maturity level of ISOcertified and non-ISO certified construction contracting organizations in the P\&S process was compared. 39 ISO-certified and 57 non-ISO certified contractor's CI maturity was analyzed using independent t-test. Although the ISO-certified organizations' CI maturity level was higher, the general maturity level was low, warranting serious consideration for the application of LPS.
\end{abstract}

\section{KEYWORDS}

Lean construction, continuous improvement, Last Planner System, ISO-certified organizations.

\section{INTRODUCTION}

The construction industry has often been "singled out" for not having taken on board improvement initiatives in an industry-wide and consistent manner to iron out key problematic areas such as timely delivery of projects, poor safety and quality standards and its adverse impact to the environment. There has been strong criticism from some quarters stating that the construction industry seems to be very much in an adversarial position in comparison to other major industries like manufacturing in embracing best

1 Associate Professor, UTHM - Universiti Tun Hussein Onn Malaysia, +6 012537 7247, cpgomez@uthm.edu.my or cpgomez21@gmail.com

2 Lecturer, UTHM - Universiti Tun Hussein Onn Malaysia, +6 019730 1780, hashima@uthm.edu.my 
practice, especially that of process improvement initiatives. However, of recent, there is evidence of increasing uptake by the construction industry.

Within the construction industry there is a general 'acceptance' regarding the notion of best practice. Practice is predominantly explained using objective terms, although it is a context-specific and transient concept and subjective in nature. In acknowledging the subjective nature of practice, and for want of amore appropriate term Gomez (n.d.) refers to "excellent practice" to imply better practice based on benchmarking. Green (2001) vehemently objects to the rhetoric of best practice, considering it to be rather prescriptive to the extent of being proffered universally as a panacea for the construction industry's problems. He apparently views lean production, partnering and business process engineering as exemplars of the predominant 'best practice' agenda, serving the narrow cost efficiency interests of the technocratic elite (Green, 2000) at the expense of broader soft human resource management considerations. Taking on a critical perspective, he argues that lean construction is not a theoretically neutral concept, he describes lean construction as just another improvement recipe that fits with the construction industry's dominant culture of 'command and control, and thus conveniently accepted as 'best practice'.

Green (2001, 2011), views generic best practice as a management fashion, shaped and judged by rhetoric of the marketplace (Green, 2001), and not contextual in nature. According to him the best practice initiatives are most willingly undertaken by a management elite aimed at perpetuating the management regime of command and control. Using a critical analytical lens, he observes that there seems to be an uncritical acceptance of the discourse of best practice, as in the case of Business Process Reengineering (BPR); which is still being highly regarded, although there is convincing research evidence that the majority of BPR initiatives fail. It is additionally claimed by him that lean production shares many of the characteristics of BPR - referring to lean production as a cocktail of ideas that includes the continuous improvement concept (Green, 2011).

This paper is presented as a timely, reflexive response to the critical view on lean construction presented by Green $(1999,2001,2011)$ and those whom he cites in support of his arguments. The earlier response provided by Howell and Ballard (1999) dismisses much of the claims made by Green (1999) against lean construction; primarily addressing his disconnect with lean construction's emphasis on reliable workflow centred around production management. In this paper, the response to much of Green's lamentations is done in the context of tackling the issue of instituting a culture of CI within construction projects through the implementation of the Last Planner System ${ }^{\circledR}$ (LPS) - as a CI management tool in planning and scheduling of projects.

It appears that Green (2011) seems too casual in his critical analysis of lean construction as a practice, loosely lumping lean construction with most of the other process improvement initiatives -leading him to assume that the so-called "best practice" initiatives such as BPR, Total Quality Management (TQM) and Lean Construction rely on generic reductionist tools and techniques. It is suggested here that by using the same critical lens, but with the benefit of having experiential knowledge, detractors would be able to appreciate that this is clearly not the case with lean construction - taking just the 
Last Planner System ${ }^{\circledR}$ (LPS) as a case in point. The lean construction community has forwarded strong criticisms with regard to the traditional monolithic systems view of construction projects resulting in vertical reductionist views and top-down approaches, like the work breakdown structure and the critical path method. Dave (2015) notes that Lean as a process improvement methodology has much to offer; stating that unlike Lean, the other major process improvement approaches do not foster a balance between the key areas of people, process and technology. The criticism levelled by Green (2011) against lean construction to be at best a 'bolt-on' model of change 'transplanted' from manufacturing is additionally disconcerting. It is important to have more than just a single lens to view how knowledge is "transferred" or rather "acquired" from other industries; as is well established with respect to process benchmarking. The technological knowledge of lean construction, as perceived here in terms of the LPS, which is taken to constitute CI practice, is seen as being "acquired" through the efforts of lean construction practitioners, that is best understood in terms of the culture acquisition model.

\section{LPS AS CONTEXTUALIZED CI PRACTICE UNDERSTOOD BASED ON THE CULTURE ACQUISITION MODEL}

The view that knowledge requires contextual adaptation, from a social constructivist perspective, is in reference to a community of knowing adopting an idea, information or knowledge from a different community of knowing, as some external ideas may not fit (Fleck, 1935/1979 cited in Tenkasi et al., 1999). Hence, it is proposed by Tenkasi et al. (1999), that the information or knowledge may have to be reconfigured or adapted to fit in with the recipient community's meaning system. They posit three different operating assumptions regarding knowledge:

- knowledge may be subjectively constructed and may be subjectively consumed;

- knowledge requires contextual adaptation;

- knowledge is incomplete.

It is in this sense, that the culture acquisition model is seen as relevant to understanding lean construction, in terms of community of practice (CoPs) of lean construction practitioners contextualizing practice that was initially developed for the manufacturing industry and producing knowledge relevant to the construction industry. The "culture acquisition model shifts our attention to the work of individuals who make and remake culture and use it for their own ends" (Henning, 1998: p. 86); rather than according to the culture transmission model, which takes the view of culture as a force that organises people. Central to the concept of the 'culture acquisition model' in the context of learning related to lean construction, is that the learner is not a passive receiver, and there is active participation as well as an emphasis on existing conceptions regarding the area of learning (see Fetherston, 1997).

As such, it is clear that Green's criticism of lean production is rather unfounded as the application of lean construction principles, although rightly acknowledged to have been "borrowed" or adapted from lean manufacturing, have been clearly contextualized. The acquired knowledge invariably supported with relevant theory, in addition to having 
undergone industry validation. The developments attributed to lean thinking are clearly based on a non-reductionist view of the construction project, with the prime motive of maximizing value and minimizing waste in the widest sense possible (a phrase that implies 'interpretive flexibility'). It cannot be denied that in order to operationalize abstract concepts, mechanisms (structure and organization) have to be relied on. Although lean construction is founded on sound principles and theories that has consistent guidelines for implementing the well-researched lean practices, there is 'interpretive flexibility'. If contextualization is a key feature of the relevance of a practice, then certain amount of interpretive flexibility, if not more, needs to be accommodated to engender more creative and significant applications. In this sense, it is argued here that the criticism accorded Lean as being amenable to interpretive flexibility, as Green (2001) views it, is rather limiting. As it clearly sits well within a constructivist notion of knowledge production, which seems to have escaped Green's consideration.

In enquiring into the nature of construction management theory Seymour et al. (1997)note that research in construction management has tended to underestimate or ignore the importance of the interpretive process. From a methodological perspective, this piece of work relies on the researcher's interpretive sense making of the limitations of ISO management systems to embed CI as a practice, whilst taking on a generative research prospect for implementing CI through the LPS for planning and scheduling to contribute to a culture of CI. In more specific terms, this paper is centred around research work aimed at investigating the extent to which the generic process improvement initiative of ISO 9000:2000 series and onwards, which has been gradually placing greater emphasis on CI, can by itself contribute to a high CI maturity level within an organization. As anticipated, it was found that ISO accredited construction contracting organizations, though having a relatively higher level of CI maturity compared to non-ISO organizations, still did not have a high level of CI maturity. Thus, this paper proposes that the application of the LPS, that is structured based on the concept of transformation, flow and value (TFV) could be key to the implementation of CI with respect to the process of Planning and Scheduling (P\&S), and thus can contribute significantly to establishing a culture of CI within construction contracting organizations. The intention is to use the LPS as a moot point to draw attention to some of the false claims forwarded by Green against the practice of lean construction. To recap: the TFV conceptual framework as proposed by Koskela (2002) supports a variety of different tools and techniques that allow the principles of Lean to be applied to the management of construction projects as part of the Lean Production Delivery System (LPDS) - the best known of these is last planner (see Ballard and Howell, 1998), which is structured on the principle of CI.

\section{REVIEWING CI WITHIN CONSTRUCTION INDUSTRY ISO QMS}

Although, there have been recent developments within the industry regarding the implementation of CI, however it is evident that this concept is being incorporated within the many generic organization-wide initiatives, such as TQM, ISO 9001:2015 and business models of organizational excellence assessment. The concept of CI was given 
serious attention based on the work of Deming. The Deming cycle (Plan, Do, Check, Act - PDCA) is a methodology for continuous improvement. This methodology, originally called the Shewhart cycle (initially was a straight line process) for statistical quality control, was developed by Walter A. Shewhart. It was renamed the Deming wheel or cycle by the Japanese in 1950. W. Edwards Deming suggested that the procedure should be followed for the improvement of any stage of production for finding a special cause of variation indicated by statistical signals (Deming Cycle, 2000). Finally, in 1951 Japanese executives developed the Deming cycle into the current PDCA cycle. By the 1960's the PDCA cycle in Japan had evolved into an improvement cycle, and a management tool. The traditional practice in CI implementation is the standard PDCA process. PDCA is often used as a framework for executing Kaizen, which refers to the process of undertaking small incremental continuous improvements in the workplace.

Based on the current scenario in Malaysia and worldwide, an increasing number of construction organizations are now accredited with ISO 9001:2015 (previously being ISO 9001:2008) Quality Management Systems (QMS) standards. ISO:9000 Quality Management Standards (QMS) is now regarded as one amongst the many business improvement methodologies, although initially thought of as a validation of standard operating procedures that are indicative of having in place processes to assure quality. It is noted by Murphy (2002), that with the release of ISO 9000:2000, an unprecedented emphasis has been placed on customer satisfaction and continual improvement. Based on the statistics provided by the Department of Standards Malaysia, updated to the $3^{\text {rd }}$ Quarter of 2017, there are 1,357 ISO 9000 QMS certified construction organizations, the highest amongst all industries. This is heartening to some extent. However, a related issue that has arisen is the perception amongst industry practitioners that having an emphasis on CI within ISO 9001:2000 series is adequate.

A key point of contention is the general perception that by embodying CI within ISO worldwide, ISO (ISO 9001:2008 recently updated to ISO 9001:2015 Quality management systems-requirements) has opened the door for all types of firms all over the world to begin their journey to excellence performance. However, as stated by Stankard (2002) “ ISO ... alone is insufficient to achieve durable competitive advantage and high performance.. it's scope is too narrow." ISO is viewed here as structured on a "push" philosophy, primarily an auditing tool aimed at guiding performance and instituting acceptable corrective actions. Whilst business excellence practice takes on a more selfassessment driven approach -however still undertaken within a reflective (reactive) mode, and unable to fully capitalize on the full benefits of CI.

The practice of CI requires an attitude that focuses on a contextualized systemic, ongoing value enhancement process with all implementations having a firm theoretical grounding. In this respect, it is important to differentiate Clause 10.3 of ISO 9001:2015 which primarily aims to impress on the organization to continuously improve the suitability, adequacy and effectiveness of the quality management system (QMS). These generic business improvement methodologies that do not have in place specifically designed-in mechanisms to undertake the practice of CI can be limiting. Additionally, for the construction project team this can be rather more problematic, taking into account the 
3 peculiarities associated with construction projects, i.e. site production; one-of-a-kind product and temporary production organization (see Koskela, 2000).

\section{AND THE LAST PLANNER SYSTEM}

$\mathrm{CI}$ as a process improvement concept is considered as being fundamental to achieving high performance. One key feature of this would entail measurement. Some key indicators of $\mathrm{CI}$ are that of performance in eliminating defects, reducing process and product waste, managing efficient production and thus improving productivity, achieved on a continuous improvement basis. Much work has been undertaken by the lean construction community on planning in design and construction underpinned by the philosophy of CI, especially the work of Ballard (2000) on the Last Planner System ${ }^{\circledR}$ (LPS). However, in general such efforts have not been well received by the wider construction management community.

The LPS is seen here as key to enabling CI within construction projects. Construction organizations intending to embed a culture of CI within their organizations have at their disposal a technique that shapes workflow and addresses project variability in construction. It is noted by Salem (2005) that in the LPS, the sequences of implementation of master schedule, reverse phase schedules (RPS), six-week look ahead, weekly work plan (WWP), percent plan complete (PPC), constraint analysis and variances analysis sets up an efficient schedule planning framework based on a pull technique, to manage work flow, sequence, and rate. The LPS matching work flow and capacity allows for developing stakeholder-devised methods in executing work and improves communication between trades. Hamzeh (2011) describes the LPS as one that challenges the old practice of developing schedules and pushing them from top management down to frontline people to execute. It advocates collaborative planning, performing collaborative constraint analysis, and learning from plan failures. He notes that the LPS institutionalizes coordination and communication by incorporating them into everyday activities and into a managerial structure for project planning and control, team building, and continuous improvement.

Sacks et al. (2010), impress the point that CI needs to be deliberate, institutionalized, and implemented as a systematic form of improvement, wherein CI goes beyond mere learning.Dave (2015) notes that Lean philosophy has gained stronger ground as a process improvement philosophy in organizations. Empowerment of people is significant in Lean as workers are given responsibility to control and improve their own processes. It is also more sustainable as it proposes close integration with suppliers to achieve a long term relationship based on trust and mutual benefit. The fundamental problem facing most improvement methodologies are that they lack a specific theoretical basis. This is not the case with CI based on the Lean theoretical framework.

\section{IS COMPLIANCE TO ISO INDICATIVE OF CI PRACTICE?}

Specifically, in construction projects, as stated by Shu-Hui and Ping (2006), one of main problems in planning and scheduling (P\&S) is the determination of the project schedule, especially when the resources required are limited, and the traditional schedule estimate often fails in optimizing the project performance. It is imperative that a continuous 
improvement process needs to be established with a feedback loop embedded within the work process using industry-specific tools and techniques. The key notion is that of 'improving'. The question to be asked is then, does and can ISO deliver aspects such as these, when ISO has its purpose of meeting generic standards. It is stated by Gomez and Hashima, (2009) that the establishment of CI as a practice for P\&S requires more "effort" than what is mandated according to ISO 9001.

It cannot be denied that in order to set in place a CI initiative, specific project-specific measures to enable improvement have to be designed and owned by the specific stakeholders. In this respect, this paper provides a comprehensive set of measures of CI practice for $\mathrm{P} \& \mathrm{~S}$ of construction projects based on having in place the particular $\mathrm{P} \& \mathrm{~S}$ work process CSFs.

\section{EMPIRICAL RESEARCH METHODOLOGY}

ACI maturity model for construction project $\mathrm{P} \& S$ process was developed as a questionnaire form in order to measure the CI practice of both ISO-certified and non-ISO certified large construction contracting organizations. From the distributed questionnaires, 39 ISO certified and 57 non-ISO certified major contractors belonging to the grade G6 and G7category responded (see Table 2).These two grades of contractors, are viewed here as major contractors. Grade 6 contractor companies are eligible to tender for projects costing not more than RM10 million whilst G7 contractors are eligible for tendering for projects costing RM10 million and above. The CI maturity model was developed based on CI critical success factors (CSFs) identified through a 3-round Delphi survey consisting of P\&S CSFs identified from literature. The Delphi expert panel consisted of initially 15 construction industry practitioners, with an average of 8 years working experience on construction projects at management level. The number of experts finally trickled down to 6 experts. A total of 8 main latent CSF constructs (see Table 1) were identified with a total of 38 observable constructs.

Table 1: The eight latent CSF constructs for planning and scheduling

\begin{tabular}{|l|l|}
\hline CSF1 & Development of Continuous Improvement System for Planning \& Scheduling (P\&S) \\
\hline CSF2 & Development of Performance Measures for P\&S \\
\hline CSF3 & Management Review for P\&S \\
\hline CSF4 & Analysis of Processes to Identify Improvement Actions \\
\hline CSF5 & Implementation of Improvement Process for P\&S \\
\hline CSF6 & Variation Management (general) for P\&S \\
\hline CSF7 & Variation Control Method for P\&S \\
\hline CSF8 & Variation Management Activities for P\&S \\
\hline
\end{tabular}

The respondents were asked to mark their organization's level of CI practice according to a five point Likert-scale for a total of 38 observable constructs of the 8 latent CSFs. SPSS software was used to undertake parametric independent t-test to compare the 
mean of the two independent samples. The feedback from questionnaires were calculated based on mean score and standard deviation. Average Index (AI) method was used to analyze the data. The scores provided by the respondents for all of the 8 main CI critical success factors for $\mathrm{P} \& S$ in the questionnaire was summed up. The total score for each of the CSFs was calculated and divided with the total number of elements for each main CSF. The average was multiplied by hundred percent to obtain the level of CI practice. The categorization of the CI maturity levels was adapted from Bessant and Caffyn (1994)and validated by the Delphi experts.

Table 2: ISO and Non-ISO Certified Companies Involved In the Survey

\begin{tabular}{|c|c|c|c|}
\hline \multirow{2}{*}{ ISO Certified Contracting Construction Organizations } & \multicolumn{3}{|c|}{ Grade of Contractors } \\
\cline { 2 - 4 } & G7 & G6 & Total \\
\hline Yes & 25 & 14 & 39 \\
\hline No & 32 & 25 & 57 \\
\hline Total & $\mathbf{5 7}$ & $\mathbf{3 9}$ & $\mathbf{9 6}$ \\
\hline
\end{tabular}

Table 3: Percentage, Grade and Description of CI Maturity Level

\begin{tabular}{|c|c|l|}
\hline LEVEL & CI MATURITY SCORE & DESCRIPTION \\
\hline $5^{\text {th }}$ Level & $90<\mathrm{CI} \leq 100 \%$ & Self-optimized CI practice implementation \\
\hline $4^{\text {th }}$ Level & $80<\mathrm{CI} \leq 90 \%$ & Excellent CI practice implementation \\
\hline $3^{\text {rd }}$ Level & $70<\mathrm{CI} \leq 80 \%$ & Clear structured implementation of CI activities \\
\hline $2^{\text {th }}$ Level & $60<\mathrm{CI} \leq 70 \%$ & Implementation of CI activities at organization level \\
\hline $1^{\text {st }}$ Level & $50<\mathrm{CI} \leq 60 \%$ & Implementation of CI practice at project level \\
\hline 0 Level & $\mathrm{CI} \leq 50 \%$ & No clear indication of CI practice. \\
\hline
\end{tabular}

\section{RESULTS}

The approach taken here is to directly relate the achievement of CSFs as indicative of the practice of CI. Table 4 below indicates the frequency of major contracting construction organizations (G6 and G7) according to the 5 levels of CI maturity. The results show that there are 6 ISO-certified organizations at the highest $5^{\text {th }}$ level CI maturity, 17 companies at level 4, and 16 companies at level 3, out of the total 39 ISO certified organizations. However, for the 57 non-ISO contracting construction organization, there were none at level 5, $3(5.3 \%)$ were confirmed to be at level 4, followed by $20(35.1 \%)$ at level 3; 26 at level $2(45.6 \%) ; 1$ at level $1(1.8 \%)$ and 7 at level $0(12.3 \%)$. The findings of this research indicates that ISO certified companies are relatively more inclined towards having a more matured CI practice. Although the results show that ISO organizations have a relatively higher level of CI maturity, the CI maturity levels are still rather low.

Table 4: CI Maturity Level of ISO and non-ISO Certified Contracting Organizations 


\begin{tabular}{|c|c|c|c|c|c|c|c|c|}
\hline \multicolumn{2}{|c|}{ CI Maturity Level } & $5^{\text {th }}$ & $4^{\text {th }}$ & $3^{\text {rd }}$ & $2^{\text {nd }}$ & $1^{\text {st }}$ & 0 & Total \\
\hline \multirow{2}{*}{$\begin{array}{c}\text { ISO certified } \\
\text { Organizations }\end{array}$} & Freq. & 6 & 17 & 16 & 0 & 0 & 0 & 39 \\
\cline { 2 - 9 } & Percent & $15.4 \%$ & $43.6 \%$ & $41.0 \%$ & $.0 \%$ & $.0 \%$ & $.0 \%$ & $100.0 \%$ \\
\hline $\begin{array}{c}\text { Non-ISO certified } \\
\text { Organizations }\end{array}$ & Freq. & 0 & 3 & 20 & 26 & 1 & 7 & 57 \\
\cline { 2 - 9 } & Percent & $.0 \%$ & $5.3 \%$ & $35.1 \%$ & $45.6 \%$ & $1.8 \%$ & $12.3 \%$ & $100.0 \%$ \\
\hline \multirow{2}{*}{ Total } & 6 & 20 & 36 & 26 & 1 & 7 & 96 \\
\cline { 2 - 9 } & $6.2 \%$ & $20.8 \%$ & $37.5 \%$ & $27.1 \%$ & $1.0 \%$ & $7.3 \%$ & $100.0 \%$ \\
\hline
\end{tabular}

The research hypotheses is as follows:

There is a significant difference in CI maturity level in the area of planning and scheduling amongst major ISO and non-ISO of construction contracting organizations.

$\mathrm{H}_{\mathrm{o}}: \mu_{\mathrm{ISO}} \neq \mu_{\text {non-ISO }}$

With respect to the research hypotheses stated above, the result of independent sample t-test shows that there are 37 correlations at significant level, $\alpha=0.05$. Whilst, the calculated probability ( $\mathrm{p}$ values) for $37 \mathrm{CSF}$ out of 38 are less than 0.05 for ISO certified and non-ISO certified large construction contracting organizations. Hence, there is a significant difference in the CI maturity level between ISO and non-ISO certified construction contracting organizations, although the CI maturity is generally not at a high level, as is evident from the results presented in Table 4.

\section{CONCLUSION AND DISCUSSION}

It is clear that many organizations are unaware of the fundamental changes needed to shift from a compliance orientation of ISO9000 standard and its variants to the form of management that places broader emphasis on $\mathrm{CI}(\mathrm{Cobb}, 2003)$. This is rather disconcerting; in view of the vast amount of evidence-based research on the implementation of lean construction principles and its related contributions to CI practice, however still facing the challenge of slow uptake. It is hoped that this paper to some extent will serve to address the current 'paradox' within the Malaysian construction industry that appears to be satisfied with seeking to implement elements of CI practice through the ISO compliance route.

This paper has set out to emphasize the point that just having in place ISO:QMS 9001: 2015 standards is insufficient to develop a culture of CI, using the CI maturity model as an indicator. This paper aptly argues for the implementation of more contextualized theoretically-grounded mechanisms to bring about greater CI maturity that can contribute to a culture of CI. The specific case in point here is that of using the Last Planner ${ }^{\circledR}$ System (LPS) to enable the implementation of CI practice within the construction project planning and scheduling process. Wherein, the TFV conceptual framework as proposed by Koskela (2002) is taken as the theoretical foundation for achieving the full potential benefits of LPS. 
The achievements in terms of CIthrough ISO:QMS 9001:2015 standards compliance are seen here as enabling organizations to grab onto the low hanging fruits of CI (to use a phrase borrowed from the sustainable development agenda). Thus, sole reliance on ISO certification is not sufficient for achieving fully the higher levels of CI maturity. In practical terms, it is important to view standards such as ISO 9001:2015 and the its variants as being complementary rather than being a competing approach in the pursuit of continuous improvement. Further research could be undertaken to investigate the level of 'readiness' of ISO 9001:2015 certified organizations compared to non-ISO certified organizations in the implementation of the different lean construction principles.

\section{ACKNOWLEDGMENTS}

We would like to thank Universiti Tun Hussein Onn Malaysia for funding the research project: Continuous improvement CSF framework for assessing CI maturity in ISO and non-ISO certified construction contracting organizations.

\section{REFERENCES}

Ballard, G. and Howell, G. (1998)."Shielding production: essentialstep in production control."Journal of Construction Engineering and Management, 124, 11-17.

Ballard, G. (2000). "The last planner system of production control" Ph.D. thesis, Univ. Birmingham, United Kingdom http://etheses.bham.ac.uk/4789/1/Ballard00PhD.pdf > (Nov. 3, 2017).

Bessant, J. and Caffyn, S. (1994)."Rediscovering Continuous Improvement." Technovation,Vol. 14, No. 1, pp.17-29.

Cobb, C.G. (2003). From quality to business excellence: A systems approach to management. Wisconsin: ASQ Quality Press

Dave, B. (2015). "Striving for Continuous Process Improvement - A Construction Case Study."Proceedings of the Indian Lean Construction Conference (ILCC 2015). pp. 13.

Deming Cycle.(2000). In: Swamidass P.M. (eds). Encyclopedia of Production and Manufacturing Management. Springer, Boston, MA.

EFQM (n.d.). "Model criteria." <http://www.efqm.org/efqm-model/model-criteria> (Jan $15,2018)$.

Fetherston, T. (1997). The Derivation of a Learning Approach Based on Personal Construct Psychology.International Journal of Science Education. Vol. 19(7), 801819.

Gomez (n.d.). "A study of the situated practice of benchmarking in the UK construction industry."

<http://eprints.uthm.edu.my/7731/4/Christy_P._Gomez_hingga_bab_4.pdf> (Dec 12, 2017).

Gomez, C.P and Hashima H. (2009). "The Continual Improvement Clause 8.5.1 of ISO 9001 and The Philosophy of Kaizen."Proceeding of 2nd Construction Industry Research Achievement International Conference (CIRAIC 2009). The Legend Hotel Putra Place, Kuala Lumpur, Malaysia. (3-5 NOV 2009). 
Green, S. (1999). "The Dark Side of Lean Construction: Exploitation and Ideology"Proceedings of the International Group for Lean Construction.

Green, S. (2001). "Towards a critical research agenda in construction management." $C I B$ World Building Congress, April 2001, Wellington, New Zealand.

Green, S. (2011). Making sense of construction improvement. John Wiley \& Sons: Chichester, UK.

Hamzeh, F.R. (2011). "The lean journey: implementing the last planner system in construction." Proceedings of the 19th Annual Conference of the International Group for Lean Construction, Lima, Peru, pp. 379-390.

Howell, G. and Ballard, G. (1999). "Bringing light to the dark side of lean construction: a response to Stuart Green", Proceedings for the 7th Annual Conference of the International Group for Lean Construction (IGLC-7), Berkeley, CA.

Karltun, A. (2011). "Developing HTO system's thinking for organizational and technological change." Proceedings of 10th International Symposium on Human Factors in Organizational Design and Management, Grahamstown, South Africa, April 4-6.

Kettinger, W.J., Teng, J.T.C. and Guha, B. (1997). "Business Process Change: A Study of Methodologies, Techniques, and Tools." MIS QuarterlyVol. 21, No. 1 (Mar., 1997), pp. 55-80

Koskela, L. (2000). An exploration towards a production theory and its application to construction.PhD Thesis, VTT Publications 408. VTTTechnical Research Centre of Finland, Espoo.

Koskela, L.J., Ballard, G, Howell, G and Tommelein, I. (2002). The foundations of lean construction. In: Design and construction: building in value , Butterworth Heinemann, Oxford, UK, pp. 211-226.

Koskela, L. (2011). "Fifty Years of Irrelevance: the Wild Goose Chase of Management Science."Proceedings of the 19th Annual Conference of the International Group for Lean Construction, Lima, Peru, pp. 85-96.

Murphy, R.J. (2002).Implementing an ISO 9001:2000 Based Quality Management System: Including Safety and Environmental Considerations. Rockville, MD: ABS Consulting Press.

Seymour, D. Crook, D. and Rooke, J. (1997)."The roleof theory in construction management: a call for a debate."Construction Management and Economics, 15(1), 117-19.

Shu-Hui J. and Ping H.S. (2006). "Construction Project Buffer Management in Scheduling Planning and Control." Proceedings of the 23rd ISARC, Tokyo, Japan. pp 858-863

Stankard, M.F. (2002). Management systems and organizational performance: The quest for excellence beyond ISO9000. Westport, CT: Quorum Books.

Tenkasi, R.V. and Morhman, S.A. (1999). Global Change as Contextual Collaborative Knowledge Creation. In Cooperrider, D.L. and Dutton, J.E. (eds.). Organization Dimensions of Global Change: No Limits to Cooperation. London: Sage, pp. 114136. 